\title{
Analysis on College Online Education Quality Management and Development Path
}

\author{
Yao Cheng \\ Sichuan Agricultural University, Sichuan Ya’an 625014, China
}

\begin{abstract}
Nowadays, with the rapid development of the internet, it becomes an important part in our daily life. In education field, online education has become a vital supplementary means in undergraduate course teaching. Undoubtedly,online teaching quality is vital to online teaching measurement and teaching quality management is a core in education management. This paper explores the path for college online education development and quality management from such three aspects as education targe positioning, online education resource configuration and teaching quality management.
\end{abstract}

Keywords: Online education; quality management; system

In order to enable online education to be a more convenient and easier education mode and achieve a practical and efficient purpose, college shall attach importance to the selection of eduction means, make a reasonable arrangement of teaching and teacher teams, trace the students' learning effects and at any time pay attentions to online education quality during implementation of online education. Only these basic management goes smooth can online education proceed smoothly.

\section{Development Course of China's College Online Education}

This is an information era nowadays. With the rapid development of computer technologies and internet technologies, under this background, online education arise at the historic moment. This kind of education mode is absolutely different from the traditional education mode. It provides a more convenient and easier way for students to study, so students can study at any time at any place. It also accelerate the development pace of lifetime education and lifetime study. Compared with the traditional eduction mode, this new online education mode has many advantages. First, it it more open and flexible in eduction means and unlimited to the time and space. Secondly, it provides a chance for learners to freely decide when and where to learn by themselves. So, it is economically affordable to some degree. Last, in terms of management, the managements save material and financial resources but also save time, so, this education mode is more time-efficient. All in all, online education mode is very popular in many colleges and becomes an education reform trend.

In 1988, China's college education online education started to be a plot. Until now, all of China's colleges have set up this education mode. Meanwhile, it attract more and more learners year by year. In 
the initial stage of online education establishment, colleges may need to invest huge material and financial recourses to mainly develop multimedia teaching resources and establish online education platforms and some teaching courseware and explore applicable management modes to this eduction mode gradually during the development course.

In short, there are many shortcomings mainly in terms of management and development of this new online education mode.

\section{Basis for Establishment of Online Education Quality Management System}

Total quality control was proposed by ARmand Vallin Feigenbaum in his enterprise management research. He is a famous America expert in 1960's. Total quality control theory refers to that a company's all production and service activities in which all staff involve shall be centered on quality management and a set perfect quality management system which is established based on management technology and professional technology and aims to meet a company's management needs. The total quality management theory is to provide more excellent service and good product quality and all departments coordinate in all activities to obtain maximal economic benefits substantially. Based on traditional management theories and in combination of the current operation management needs, this set of theory develops into a new scientific management system. Although this set of theory is mainly applicable to economy, it also can provide references for online education management. It is suggested to establish a perfect online education management system centered on students' satisfaction. Colleges needs to have enough understanding of the importance of in-place management and services to achieve a scientific development concept putting students first. Only when each subsystem goes efficiently can a sustainable development of the whole management system be ensured.

In addition, this set of theory takes all aspects of total quality management into consideration. Its tasks are interlinked and affect each other mutually in various components of this system and there are also interactions between the various systems. The systematical method is mainly to perform integrated and comprehensive investigation of various components in the system and their interlinks and to improve continuously the relationships between various components to enable this system to achieve the best effects. This set of scientific method is able to provide favorable conditions for the online eduction management systems. That is to say, various components of online eduction system needs to be independent and interlinked so as to ensure a stable and sustainable development of the whole system. These components are an organic integration. Whichever component goes wrong may affect the quality of the whole online education system.

Thus, both the total quality management theory and systematical scientific theory fully take the relationships between the whole system and its various components into considerations. Those theories are very useful for online education management for references. That is, various components of online eduction quality system are independent and interlinked. whichever component goes wrong may affect the service quality of the whole online education quality system. Thus, it is required to balance the relationships between various components, because 
these components form an integrated online eduction service system.

\section{Strategies for Establishment of Online Education Quality Management and Development System}

Online education is one of the important identifiers in modernization education and has become a modern eduction trend. Under this era background, to establish a perfect online education management system, it is necessary to discuss it from the following aspects.

First, it is suggested that people should change his opinions on online eduction and accept this education mode. Moreover, it is necessary to specify the social functions of modern online education which does not stop at academic credentials education but focuses on continuous eduction. This thought also meets the requirements for the development and the actuality of China's education and absolutely meets the requirements specified in National Medium and Long-term Education Reform and Development Plan Outline. The online education is decided by the era and social development and the development of lifetime education theories and practices of education socialization and social education. Online education shall, according to its orientation, establish its professional structure to meet the social needs to enable online education to be more practical and have era marks, but also reflect its advantages to help students to solve any problems they encounter in their daily life and increase their allaround quality to achieve the purposes of combining the study with scientific researches to enable learners to not only learn professional knowledge but also be able to apply their learned knowledge to the practice to cultivate high quality and practical talents.

Second, set online education quality goals. Online education is a practical education but also provides an easy way for lifetime learning. The essence of online education is to accelerate the stable development of a learning society and create an environment for people to learn at any time and at any place so as to enable learners to enrich their life and their knowledge and improve their skills at any time, but also be better educated and increase professional skills to possess comprehensive abilities to meet the economic and social development needs. In order to achieve the foregoing effects, online education teachers having senior professional title shall account for more than $80 \%$ of the total teachers. Online education shall have diversified contents and cover kinds of training programs at all levels, including graduate, undergraduate and specialist. Moreover, there shall be more than $70 \%$ of learners satisfied. Only after these are achieved can quality be ensured to certain extent.

Third, implement dynamic management of online education. We know from curriculum theory that every curriculum develops in a dynamic way. Also, online education curricula have this characteristic. Before implementation of online education, certain understanding of the social development as well as various kinds of group in the society is necessary. Meanwhile, it is necessary to study on the needs of the new emerging industries and the whole society. In addition, the curricula shall be practical, targeted and prospective.

Fourth, a professional management team is vital to online education. A professional online education management includes teaching resource managements, coordinators, developers and executors who are very vital to the management of online education 
resources, including hardware and software. The allocation of staff in all departments and teaching quality are an important part in the online education management system, decides the development of the online education and plays an important role in online teaching. Managements are mainly responsible for helping learners in their study, uploads of learning materials and online Q \& A in their routine work.

Fifth, establish a professional teacher team. In an online education quality management system, an excellent teacher team which have strong sense of responsibility is vital to increase online education quality. Unlike traditional education mode, only education is characterized by independence, selectivity and consciousness. So, the teachers are not a core like in the traditional education. The core of the online education is the online platform managements who are the directors of the learners. The role is charge, so teachers having professional dedication are needed to take this role.

Sixth, establish a perfect system supporting online learning. First, online education management platform establishes a perfect online learning system and online managements release latest online teaching plans and excellent curricula and provide the latest and best learning resources for learners. Also, directors can call learners, send emails to learners or talk to learners in QQ to know how the learners' learning goes and help them to overcome any learning difficulties at any time and adhere to teaching and learning interactions. Secondly, it is important to share online education resources of all colleges and make fully use of these resources. For example, open online libraries and Ereading rooms to learners for free to enable learners to benefit from informationization. Last, establish a stronger and stronger informationization teaching mode. We know, under the informationization background, education incorporate some traditional teaching contents into online teaching.

\section{Conclusions}

In short, online curricula, online information and teachers are the priorities of online education management system. These three factors are the base and prerequisite of online education. We believe reasonably that with the further development of information technologies and the increase of online education quality, as an important assistance means in undergraduate teaching, online education will develop rapidly and efficiently in the future.

\section{References}

[1] Minutes of Fourteenth Annual Conference of China's Geophysical Society. Year 1999 Annual of China's Geophysical Society-Memoir of the Fifteenth Annual of China's Geophysical Society. 2010.

[2] Zhou Zhen. Several System Science Principles and College Preparation Management. National Youth Management Science and System Science Memoir, Volume 5 .2010.

[3] Li Zhuyu, He Xiaoxing. Quantitative Analysis of Study on China's College Teachers' Mental Pressure and Physical and Health Health; Memoir of the China's Ninth Academic Annual Site Statistics Seminar.2010

[4] Xia Zhiping. My Humble Opinion on Acupuncture Talent Cultivation; Commemoration of the $100^{\text {th }}$ Birth of Mr. Cheng Dan'an \& International Acupuncture Development Academic Seminar Memoir . 1998. 